\title{
HABITAR EM RISCO: MOBILIDADE E VULNERABILIDADE NA EXPERIÊNCIA METROPOLITANA
}

\author{
(Eduardo Marandola Jr, 2014)
}

Fernanda Cristina de Paula

\begin{abstract}
"[...] que é habitar em risco? É todo o habitar contemporâneo?

Sim, todo o habitar é um habitar em risco. Isto não se dá em virtude da sua essência, mas por causa da essência da metrópole contemporânea" Eduardo Marandola Jr.
\end{abstract}

\section{Uma fenomenologia geográfica}

O livro "Habitar em risco: mobilidade e vulnerabilidade na experiência metropolitana”, do geógrafo Eduardo Marandola Jr., é uma fenomenologia geográfica do habitar metropolitano contemporâneo; e a partir desta fenomenologia geográfica, Marandola Jr. busca compreender riscos, perigos e vulnerabilidades associados a esse habitar.

O livro lida com um conjunto de noções que vêm sendo, nas últimas décadas, um dos principais pontos de contato entre políticas públicas e a reflexão acadêmica, os conceitos de risco, perigo, vulnerabilidade. São diversas as orientações teóricas e as metodologias que discutiram e continuam discutindo esses três conceitos, no que poderíamos chamar de uma busca sistemática de pensar, decompor, buscar as causas, medir a amplitude e a profundidade de eventos ou situações danosos, negativos. Neste contexto, de um modo geral, risco veio sendo pensado como potencial de concretização de perigo, perigo corresponderia ao evento danoso e a vulnerabilidade seria o grau de exposição ao dano.

A difusão desses três conceitos, tanto no âmbito acadêmico quanto no político, é flagrante: existem, atualmente, diversos indicadores e mapas de vulnerabilidades; existem mensurações de diferentes vulnerabilidades (social, socioeconômica, à fome, à riscos naturais, etc.); existem análises de riscos, perigos e vulnerabilidade concernentes à parcelas de população, cidades ou países. Dentro deste contexto, o livro de Marandola Jr. aparece propondo uma reflexão fenomenológica geográfica de risco, perigo e vulnerabilidade. Mas o que seria um pensamento fenomenológico geográfico destes três conceitos?
Um pensamento fenomenológico geográfico do risco, perigo e vulnerabilidade, tal como desenvolvido pelo autor, começa por uma busca de compreensão dessas noções como fenômenos vividos. Começa por uma indagação pela experiência das pessoas, pelo o que, no dia-a-dia, na experiência, seja risco, perigo, vulnerabilidade. Acrescida à dimensão experiencial dos riscos, perigos e vulnerabilidades, Marandola Jr. destaca que esta dimensão experiencial é, sempre, espacial; em outras palavras, a experiência do risco, do perigo e da vulnerabilidade se dá nos lugares, pelos lugares, nas articulações entre eles, nas formas como as pessoas se relacionam com eles.

O autor sublinha que, há, portanto, uma dimensão geográfica dos riscos, perigos e vulnerabilidade e que a geografia participa da ontologia desses fenômenos. E é a partir deste ponto que a reflexão de Marandola Jr. contribui para um aprofundamento da compreensão desta tríade de conceitos: abordando-a a partir dos sentidos do viver metropolitano, lhes indagando a partir dos lugares, a partir da forma como habitamos os lugares.

A discussão desenvolvida no livro está dividida em três partes: "Geografia dos Riscos", "A Região e as Cidades" e "Habitar a Metrópole".

Na primeira parte, o autor contextualiza como risco, perigo e vulnerabilidade vieram sendo pesquisados pela academia científica. A partir de uma reflexão voltada para os sentidos desses conceitos enquanto fenômenos, revela-os como uma faceta de um contemporâneo marcado pelas sensações de incerteza e insegurança.

Nesse debate, a constatação da dimensão geográfica destes fenômenos encaminha a discussão não só para uma ontologia geográfica do risco, perigo e vulnerabilidade, mas também e necessariamente, para uma ontologia geográfica do próprio Ser. Na subseção intitulada "O Sentido Ontológico do Habitar”, Marandola Jr., a partir do pensamento sobre espaço do fenomenólogo Martin Heidegger, desenvolve uma reflexão sobre o fenômeno habitar, apontando-o como essência da relação homemmeio, modo próprio de o homem ser e estar no mundo. 
E é esse sentido ontológico do habitar que orienta toda a construção teórico-metodológica da pesquisa.

A segunda parte do livro, "A Região e as Cidades", é dedicada a um duplo movimento. Um é o de presentificar o metropolitano pesquisado (Região Metropolitana de Campinas, Estado de São Paulo), articulando essa presentificação a uma reflexão sobre o sentido ontológico de metrópole. O segundo movimento é a discussão dos procedimentos teórico-metodológicos que visam abordar o habitar metropolitano; onde se destacam a construção de metodologias geográficas orientadas pela Fenomenologia. Essas metodologias se congregam na abordagem/conceito, desenvolvido pelo autor, denominado "espaço de vida".

A terceira parte, "Habitar a metrópole" é dedicada à própria experiência do habitar metropolitano, trazido a partir dos espaços de vida de moradores da região pesquisada. A partir desses espaços de vida, Marandola Jr. revela a experiência de viver a metrópole e, nessa experiência, a manifestação de risco, perigo e, mesmo, a reflexão sobre uma vulnerabilidade até então nunca discutida nos estudos de risco, perigos e vulnerabilidade: a vulnerabilidade existencial. $\mathrm{O}$ autor destaca que, nesta vulnerabilidade, a casa, o bairro, as territorialidades que constituímos têm seus pesos tanto enquanto orientadores de nossa forma de habitar e, por conseguinte, como elementos de nossa segurança existencial. É nesse sentido que Marandola Jr. apresenta uma série de questionamentos, tece reflexões e abre caminhos concernentes à compreensão do sentido da casa, da cidade, da metrópole, do habitar metropolitano.

O livro Habitar em Risco é uma dupla contribuição em um único projeto. De um lado, enquanto fenomenologia geográfica da tríade riscos, perigos, vulnerabilidade e do habitar metropolitano, reenvia a reflexão dessas noções à concretude de suas existências, aproximando o que muitas vezes é apresentando enquanto pólos opostos e distantes: o conhecimento científico e a vida das pessoas, as quais esse conhecimento busca compreender e, mesmo, intervir. Por outro lado, esse retorno às coisas nelas mesmas, conduz e reconduz o pensamento do autor em direção a uma ontologia geográfica, a qual, necessariamente, não é uma contribuição somente para aprofundar a compreensão de riscos, perigos e vulnerabilidade, mas também, enquanto ontologia, é uma abertura de caminhos em direção a outras formas de pensar o homem, os lugares, a geografia e o fazer ciência.

\section{Referência}

Marandola Jr., E. (2014). Habitar em risco: mobilidade e vulnerabilidade na experiência metropolitana. São Paulo: Blucher, 250p.
Fernanda Cristina de Paula - Possui Bacharelado e Licenciatura em Geografia, Mestrado em Geografia pela Universidade Estadual de Campinas, foi docente da Pontifícia Universidade Católica de Campinas e atualmente é Doutoranda em Geografia, no Instituto de Geociências/ Universidade Estadual de Campinas e integrante do Grupo de Pesquisa Geografia Humanista Cultural (EAU-FAU/ UFF). E-mail: depaula. fernandac@yahoo.com.br 